\title{
LEI DE ACESSO À INFORMAÇÃO: EM BUSCA DA TRANSPARÊNCIA E DO COMBATE À CORRUPÇÃO
}

\author{
LEY DE ACCESO A LA INFORMACIÓN: EN BUSCA DE \\ TRANSPARENCIA Y LUCHA CONTRA LA CORRUPCIÓN
}

Simone Assis Medeiros - siamedeiros@biblioteca.ufla.br Mestre em Administração Pública pela Universidade Federal de Lavras (UFLA). Bibliotecária/Documentalista da UFLA.

Roberto Magalhães - magalhaes_rm@hotmail.com Mestre em Administração Pública pela Universidade Federal de Lavras (UFLA). Advogado da UFLA.

José Roberto Pereira - jrobpereira25@yahoo.com.br Doutor em Sociologia pela Universidade de Brasília (UnB). Professor da Universidade Federal de Lavras (UFLA).

\section{RESUMO}

Introdução: O direito de acesso à informação tem ganhado um destaque, cada vez maior. Sua importância tem sido ressaltada por acadêmicos, pelos especialistas, pela mídia e até pelos governos.

Objetivo: $O$ artigo tem como objetivo analisar o alcance da Lei $12.527 / 11$ no combate a corrupção e sua contribuição para a consolidação da democracia no Brasil.

Metodologia: Como técnica de pesquisa adotou-se uma abordagem qualitativa, utilizandose de revisão bibliográfica e pesquisa documental.

Resultados: A lei $12.527 / 11$ se mostra um avanço na efetivação do direito ao acesso à informação. Dentre os aspectos relevantes, pode-se citar a estipulação de prazos razoáveis para a obtenção de informações junto aos órgãos públicos, o uso das tecnologias da informação e de comunicação como facilitador do acesso às informaç̧ões públicas.

Conclusões: Conclui-se que para construção de uma verdadeira democracia, torna-se indispensável o acesso claro e transparente à informação pública, além de uma maior participação popular, fortalecendo assim os sistemas democráticos.

Palavras-chave: Lei de acesso a informação. Transparência pública. Corrupção. 


\section{INTRODUÇÃO}

Por promover a participação democrática, o direito à informação ganha um enfoque considerável com a promulgação da Lei 12.527, em 18 de novembro de 2011(BRASIL, 2011c), a qual vem dispor sobre os procedimentos a serem observados pela União, Estados, Distrito Federal e Municípios, com o fim de garantir o acesso a informações previsto em nossa Constituição Federal. Tal legislação, um tanto quanto progressista, almeja promover a ampla efetivação deste direito humano fundamental. De acordo com Bertazzi (2011) com a reabertura democrática e a promulgação da Constituição Federal de 1988, o acesso a informação pública foi elevado ao patamar de direito fundamental, previsto no Art. 5, XIV, XXXIII, XXXIV, LXXII, bem como o Art. 37. O acesso à informação como direito fundamental também é reconhecido por importantes organismos da comunidade internacional, como a Organização das Nações Unidas (ONU) e a Organização dos Estados Americanos (OEA) (BRASIL, 2011a).

Quando se propõe debater sobre a democracia, as relações entre Estado e cidadão se mostram inefastáveis. A democracia pressupõe o atendimento do interesse público em detrimento a interesses particulares. Para Tocqueville (1998) a vantagem real da democracia não é como já se disse favorecer a prosperidade de todos, mas apenas servir ao bem estar do maior número.

Neste contexto, a participação popular se faz essencial como uma forma de se garantir o bem coletivo. Mecanismos democráticos, dentre os quais se insere 0 acesso à informação, são indispensáveis para a promoção de uma maior transparência e consequentemente, menos corrupção. A transparência no acesso às informações auxilia a promover a confiança da população no governo e viabiliza sua prestação de contas. É também uma ferramenta no combate à corrupção e outras formas de irregularidades públicas. O direito à informação é, assim, um instrumento essencial para a promoção de boa governança, além de favorecer outros benefícios sociais (ARTIGO 19, 2009).

O artigo tem por objetivo analisar o alcance da lei $12.507 / 11$ no combate a corrupção e sua contribuição para a consolidação da democracia no Brasil. Se propõe a demonstrar que a legislação em estudo traz aspectos positivos para a democracia, ao fornecer mecanismos eficientes na busca ao acesso à informação, 
abordando, ainda, sua eficácia como forma de transparência pública. A análise do tema justifica-se devido à relevância que ele tem recebido, inclusive no contexto global, onde cada vez mais países têm positivado legislações com intuito de acesso à informação.

No primeiro momento, faz-se uma breve análise do surgimento da legislação sobre o acesso à informação num contexto mundial, bem como o momento de aquisição do status de direito humano fundamental. Após, passa-se a discutir o acesso à informação pública no Brasil, a partir do golpe militar de 1964, com a inclusão desse direito na Constituição Federal de 1988 e a promulgação da Lei 12.527/11. No tópico posterior aborda-se a legislação como forma de transparência pública e combate a corrupção, enfatizando as possíveis causas e consequências desta última na sociedade brasileira. Por fim, passa-se a análise da lei 12.527/11, ressaltando suas possibilidades e entraves no combate à corrupção e na contribuição para a consolidação da democracia.

\section{O ACESSO À INFORMAÇÃO PÚBLICA COMO DIREITO FUNDAMENTAL}

O direito de acesso à informação tem ganhado um destaque, cada vez maior, na pauta do dia. Sua importância tem sido ressaltada por acadêmicos, pelos especialistas, pela mídia e até pelos governos. Porém, a temática não é nova, seus debates percorrem um longo caminho.

Considerada uma das bases do sistema interamericano dos Direitos Humanos, a Convenção Americana de Direitos Humanos, também conhecida por Pacto de São José da Costa Rica, foi subscrita no ano de 1969 e entrou em vigência a 18 de julho de 1978. Em seu artigo 13 é possível observar a prescrição de que "Toda pessoa tem o direito à liberdade de pensamento e de expressão. Esse direito inclui a liberdade de procurar, receber e difundir informações e ideias de qualquer natureza [...]." (CONVENÇÃO..., 1992).

Leis que tem por objetivo concretizar o direito de acesso à informação existem há mais de 200 anos, contudo, a grande maioria é recente. Nos últimos quinze anos, inúmeras leis neste sentido foram aprovadas em países de todas as regiões do mundo, enquanto uns vultosos números de outros países assumiram o compromisso de adotar leis de direito a informação. 
Conforme Mendel (2009) a história das leis de direito a informação remonta à Suécia, onde, uma lei a esse respeito está em vigor desde 1766. Outro país com um extenso histórico de legislação sobre direito à informação é a Colômbia, cujo Código de Organização Política e Municipal de 1888 permitia aos indivíduos solicitar documentos sob o controle de órgãos governamentais ou contidos em arquivos do governo. Os EUA aprovaram uma lei de direito a informação em 1967, que foi seguida por legislação na Dinamarca (1970), Noruega (1970), França (1978), Países Baixos (1978), Austrália (1982), Canadá (1982) e Nova Zelândia (1982).

Um relatório de 2006, lista 69 países com leis de direito a informação, juntamente com outros cinco com regulamentos e normas nacionais de direito a informação. Desde então foi adotada uma série de leis, incluindo países como China, Jordânia e Nepal. Há, portanto, uma tendência global muito expressiva na intenção de adotar legislação sobre direito à informação. $O$ imperativo crescente de se aprovar legislação sobre direito à informação é um indício desta situação.

Devido seu alcance, pode-se afirmar que países de todas as regiões do mundo adotaram leis de direito a informação, o que demonstra o consenso deste direito ser fundamental para o alcance da democracia.

Em nosso país, os mecanismos de informação pública são contemporâneos. Nos lacônicos períodos democráticos que precederam o golpe militar de 1964 , pouco se preocupava com a publicidade dos atos do Estado. Não era de se esperar outra situação, já que o patrimonialismo era característica marcante no Estado naquele período, não contribuindo para qualquer mobilização neste sentido.

Com o fim da ditadura militar e a busca pela redemocratização do país, o acesso à informação ganha espaço, sendo incluído no bojo da nova Constituição de 1988. Em seu texto, passam a figurar três mecanismos garantindo este direito, previsto no inciso XXXIII do art. $5^{\circ}$, no inciso II do $\S 3^{\circ}$ do art. 37 e no $\S 2^{\circ}$ do art. 216.

Embora previsto no texto constitucional desde sua promulgação, em 1988, o direito de informação carecia de um instrumento legislativo que regulasse tal direito. Pelo contrário, o que se percebeu foi que, em nosso país, foi uma cultura pródiga de produzir decretos e legislações sobre o sigilo de documentos públicos.

A publicação da Lei 12.527 representa um marco na conquista pela informação, já que, na sua falta "o cidadão e a sociedade civil ficam, portanto, a depender da discricionariedade burocrática, situação perniciosa para a construção 
de uma administração pública transparente" (GRAU, 2006 apud BERTAZZI, 2011. p. 26).

A Lei 12.527 foi promulgada em 18 de novembro de 2011 e entrou em vigor em maio de 2012. Com a sanção da Lei de Acesso à Informação Pública, o Brasil passa a ser o 89ำ país a ter uma legislação específica para regulamentar o assunto. Na América Latina, o país será o $19^{\circ}$ a adotar esse tipo de lei.

\section{LEI DE ACESSO À INFORMAÇÃO PÚBLICA COMO MEIO DE TRANSPARÊNCIA E COMBATE A CORRUPÇÃO}

Em qualquer atmosfera democrática, deve-se ter em mente que o interesse público caracteriza-se como objetivo primordial. Ocorre, porém, que se torna difícil garantir o interesse público sem que haja mecanismos de controle democrático. Tais mecanismos servem, sobretudo, para evitar que o interesse privado sobressaia ao público, jogando por terra toda busca por democracia. Conforme Jasmim (2005, p. 47) "a sociedade democrática é concebida como uma totalidade social cujas partes, funcionalmente interdependentes, relacionam-se de modo dinâmico para adequar-se ao princípio gerador que as unifica".

Nas sociedades onde existe pouca transparência nos atos da administração pública são comuns as práticas paternalistas, clientelistas, corrupções e outras formas de utilização dos bens públicos para atingir interesses particulares. Por esta razão, esforços têm sido empregados com mais frequência na tentativa de promoção de uma maior transparência das ações governamentais. Isso ocorre porque a melhora do acesso à informação pública e a criação de regras que permitem a disseminação das informações produzidas pelo governo reduzem o escopo dos abusos que podem ser cometidos (STIGLITZ, 2002).

Precisamos nos conscientizar da tendência contemporânea que busca a parceria entre o governo e cidadão com sua participação ativa na tomada de decisões e na formulação de políticas públicas. Conforme Dahl (2001, p. 110) "cidadãos silenciosos podem ser perfeitos para um governante autoritário, mas seriam desastrosos para uma democracia". Práticas desta natureza favorecem a transparência governamental e a redução de abusos cometidos pelas autoridades governamentais. 
Para Lopes (2007, p. 10):

As políticas que tenham o objetivo de promover acesso à informação pública implicam necessariamente ações que possibilitem acesso a fóruns plurais de discussões, a instituições que prestem contas ao cidadão, a leis de acesso à informação, a proteções contra a negação de prestação de informações por parte de órgãos públicos e à liberdade de imprensa.

O uso de mecanismos de controle público, donde se inclui o direito à informação pública serve, indubitavelmente, para aproximar o cidadão dos atos governamentais, garantindo maior transparência.

No primeiro momento cabe definir corrupção, para Silva (1996) o termo corrupção tem origem na palavra latina corruptione, que significa decomposição, putrefação, depravação, desmoralização, sedução e suborno.

Segundo Klitgaard (1994, p. 40);

Corrupção é o comportamento que se desvia dos deveres formais de uma função pública devido a interesses privados (pessoais, familiares, de grupo fechado) de natureza pecuniária ou para melhorar o status, ou que viola regras contra o exercício de certos tipos de comportamento ligados a interesses privados.

O combate a corrupção é um tema que vem sendo muito debatido na agenda política do país, após o período ditatorial e a vigência da democracia. Na literatura encontramos vários relatos sobre a corrupção no decorrer da história, mas no artigo não abordaremos a questão histórica. Mas percebe-se que o problema acompanha as sociedades há muitos séculos.

No Brasil, o fenômeno corrupção também não é algo novo, possui bases históricas desde os períodos da colonização. As estruturas sócio-políticas foram contaminadas por elementos dessa colonização e encontramos resquícios na sociedade brasileira até os dias atuais elementos que fomentaram ao longo da história a prática da corrupção. Entre eles o coronelismo, o patrimonialismo e o clientelismo marcados pelo trato da coisa pública enquanto privado. Diante dessa perspectiva, percebe-se a herança deixada pela colonização nos dias atuais.

De acordo com Santos (2008, p. 128) a corrupção atravessa séculos, culturas e sistemas políticos, por certo, mas nem por isso deixa de ter um aparente denominador comum em todas as manifestações. Carvalho (2008) diz que a 
corrupção atual mudou seu sentido há 100 anos atrás. As acusações de corrupção dirigidas ao Império e a Primeira Republica não se referiram a pessoas, mas principalmente ao sistema. A partir de 1945, segundo ele ouve uma alteração semântica no seu conceito. "A oposição a Vargas, comandada pelos políticos da UDN, voltou suas baterias contra a corrupção individual, contra a falta de moralidade das pessoas. Corruptos eram os indivíduos, os políticos getulistas, o próprio Vargas" (CARVALHO, 2008, p. 238).

Segundo um estudo da Pesquisa Social Brasileira (PESB), apresentada por Almeida (2007) pode-se entender por que a cultura da corrupção é tão enraizada entre nós.

A pesquisa mostra que isso acontece porque a corrupção não é simplesmente a obra perversa de nossos políticos e governantes. Sob a simpática expressão "jeitinho brasileiro", ela é socialmente aceita, conta com o apoio da população, que a encara como tolerável.

Mas segundo Almeida (2007) as diferenças mais importantes entre os brasileiros quanto à classificação moral das situações do dia-a-dia ocorrem entre as faixas de escolaridade. À medida que a escolaridade aumenta as pessoas tendem a julgar certas atitudes como corrupção. Então, só por meio da educação é possível conquistar a maioridade política e social da população. "O cidadão esclarecido é sem dúvida uma peça incômoda, reivindicadora. Sem ele, no entanto, está comprometido nosso próprio futuro como nação" (CARVALHO, 1998, p. 287-288). Hoje está cada vez mais arraigada a convicção de que a educação constitui uma das armas mais poderosas de que dispomos para forjar o futuro (DELORS, 1996). Por isso, investimentos em educação são tão importantes para a busca da cidadania.

A qualidade da democracia aumenta quando a população é mais escolarizada, a democracia só é possível em sociedades com níveis elevados de escolarização (ALMEIDA, 2007, p. 18). Mas segundo as palavras de Viana (1999, p. 487):

O povo brasileiro nunca teve escolas que o preparassem para a democracia. Nem como homem da cidade, nem como homem do campo - o nosso homem do povo nunca pode organizar instituições sociais que educassem na prática do direito de voto e na tradição de escolha dos seus administradores e dirigentes, habituando-o a manejar esta pequenina arma delicada: uma cédula de eleitor. 
Para Garcia (2004) a corrupção esta associada à fragilidade dos padrões éticos da sociedade, os quais refletem sobre a ética do agente público. Sendo este, um mero "exemplar" do meio que vive, onde a vantagem indevida é vista como prática comum pelos cidadãos e certamente esta concepção seja mantida pelo agente nas relações a que venha estabelecer com o poder público. Para ele, os desvios de comportamentais de hoje em muito refletem situações passadas, das quais constituem mera continuação:

Para Lopes (2009) a corrupção, ao contrário do que indica o senso comum, não nasce primordialmente da falha de caráter de agentes individuais e sim de todo um arranjo político propício à sua sobrevivência. Entre os fatores que contribuem para essa realidade estão políticas governamentais, programas concebidos e administrados insatisfatoriamente, instituições deficientes, mecanismos inadequados de controle e avaliação, baixa organização da sociedade civil, sistema de justiça criminal fraco, remuneração inadequada de servidores públicos e falta de responsabilidade e transparência (ORGANIZAÇÃO DAS NAÇÕES UNIDAS, 2011).

A corrupção traz grandes perdas para a sociedade, como arrecadação tributária, inflação, impacto na riqueza, redução do crescimento econômico e de incentivos aos investimentos privados. Também reduz a renda per capita, aumenta a mortalidade infantil, além de impactar negativamente os indicadores de saúde, de educação, de produtividade (LOPES, 2007).

Uma possível explicação para o aumento dos níveis de corrupção também seja a falta de participação popular. Atualmente muito se questiona o porquê da falta de interesse da população com as questões políticas do país, sua falta de iniciativa, desinteresse. A população indigna-se com os escândalos de corrupção, aumentos salariais dos políticos, desigualdades sociais, mas tudo se resume em um povo passivo ao invés de povo ativo como mencionado por Mülher (2000).

Neste sentido observa-se as palavras de Faoro (2000, p. 442-443),

O governo tudo sabe, administra e provê. Ele faz a opinião, distribui a riqueza e qualifica os opulentos. O súdito, turvado com a rocha que Ihe rouba o sol e as iniciativas, tudo espera da administração pública, nas suas dificuldades grandes e pequenas, confiando, nas horas de agonia, no milagre saído das câmaras do paço ou dos ministérios. Esse perigoso complexo psicológico inibe, há séculos, o povo, certo de que o Estado não é ele, mas uma entidade maior, abstrata e soberana. 
O que vemos atualmente é uma relação de submissão, de espera, que Carvalho (2009) explica como uma cultura orientada mais para o Estado do que para a representação é o que chamamos de "estadania", em contraste com a cidadania. Nesse momento, buscando uma ruptura, a solução seria uma maior interação entre a sociedade e o Estado, através do contrato social, como citado por Santos (1998, p. 6), Segundo ele:

O contrato social visa criar um paradigma sócio-político que produz de maneira normal, constante e consistente quatro bens públicos: legitimidade da governação, bem estar econômico e social, segurança e identidade coletiva. Estes bens públicos só são realizáveis em conjunto: são, no fundo, modos diferentes mais convergentes de realizar o bem comum e a vontade geral.

A partir do momento que a população valorizar o local onde reside, buscará uma maior participação junto à esfera política e social do seu município e consequentemente do seu país. Do contrário, "quando as exigências de excelência no exercício de cidadania deixam de dar o tom, isso significa que esse mesmo exercício não mais pode depender de que todos os cidadãos façam da atividade política o centro de suas preocupações" (ARAUJO, 2000, p. 26).

\section{A LEI 12527/2011: SEUS LIMITES E SUAS POSSIBILIDADES}

Tal legislação pode ser considerada ampla e progressista, criada com o intuito de ditar normas para assegurar a proteção deste direito humano fundamental de acesso à informação. O conceito de informação é dado pela própria lei, que a define como "dados, processados ou não, que podem ser utilizados para produção e transmissão de conhecimento, contidos em qualquer meio, suporte ou formato." (BRASIL, 2011c).

Conforme 0 artigo $2^{\circ}$ da lei $12.527 / 11$, os procedimentos previstos nesta legislação aplicam-se à União, Estados, Distrito Federal e Municípios, porém, não se limita a eles. Contempla, também, quaisquer dos órgãos públicos integrantes da administração direta dos Poderes Executivo, Legislativo, incluindo as Cortes de Contas, e Judiciário e do Ministério Público, além das autarquias, as fundações públicas, as empresas públicas, as sociedades de economia mista e demais entidades controladas direta ou indiretamente pela União, Estados, Distrito Federal e 
Municípios.

A criação da lei 12.527/2011 vem ao encontro da tendência da burocracia estatal em manter sigilo dos seus atos. Seu texto contém diretrizes dentre as quais a observância da publicidade como preceito geral e do sigilo como exceção, uma vez que o domínio da informação seria uma inegável fonte de poder. Segundo Lopes (2007) a falta de informação pública é justamente um dos diversos fatores que motivaram a persistência de comportamentos pré-burocráticos, remanescentes de uma administração patrimonialista. Tendo como característica principal o sigilo no trato da coisa pública. Poulantzas (1985, p. 67) aborda bem o tema nessa citação:

Tudo se passa como se nesse estado de fala aberta e língua nacional unificada, o segredo em relação às massas populares e à cristalização do saber-poder estivessem passados inteiramente na escrita do Estado, cujo hermetismo como referência às massas populares, excluídas dessa escrita, é assaz conhecido. Foi esse Estado que sistematizou, quando não descobriu, a gramática e a ortografia montando-as em redes de poder.

Sem a garantia de acesso à informação torna-se inviável a atuação maciça neste sistema de freios e contrapesos. A mudança neste paradigma acarretará como consequência a diminuição do poder daqueles que detém o monopólio das informações, democratizando seu acesso à população. Para a Controladoria Geral da União (BRASIL, 2011a, p. 8):

O acesso a esses dados - que compõem documentos, arquivos, estatísticas - constitui-se em um dos fundamentos para a consolidação da democracia, ao fortalecer a capacidade dos indivíduos de participar de modo efetivo da tomada de decisões que os afeta.

Ainda segundo a Controladoria Geral da União (BRASIL, 2011a), o cidadão bem informado tem melhores condições de conhecer e acessar outros direitos essenciais, como saúde, educação e benefícios sociais. Na cultura de acesso, o fluxo de informações favorece a tomada de decisões, a boa gestão de políticas públicas e a inclusão do cidadão. Dessa forma, "o acesso a informação constitui uma ferramenta essencial para combater a corrupção, transforma em realidade o princípio da transparência na gestão pública e melhora a qualidade das nossas democracias" (MANZANO FILHO, 2012). 
Viramos a regra do jogo, como exposto por Canela e Nascimento (2009, p. 35):

\begin{abstract}
A população saberá que as informações públicas são um bem de propriedade de todos os brasileiros [...] e não um instrumento de poder deste ou daquele governante, deste ou daquele funcionário público. Os corruptores e os corruptos que se escondem sob o manto da desinformação e do segredo serão expostos pelo dever da transparência, pela luz do dia. A ética e os éticos só tendem a ganhar.
\end{abstract}

Stiglitz (2002) ao pontuar sobre a transparência dos atos do governo vem relatar que segredos foram à marca principal dos Estados totalitários que arruinaram o século $X X$ e, ainda que o público tenha interesse na transparência, funcionários são incentivados a manter o sigilo mesmo em sociedades democráticas. "Na cultura de segredo a informação é retida e, muitas vezes, perdida. A gestão pública perde em eficiência, o cidadão não exerce um direito e o Estado não cumpre seu dever" (BRASIL, 2011a, p. 12).

A falta de aptidão ética demonstrada pelos governantes faz surgir à necessidade de mecanismos de controle sociais, dentre os quais está inserida a accountabillty. O termo não possui tradução em português, embora nas palavras de Jardim (1999) possa ser definido como o conjunto de mecanismos e procedimentos que levam os decisores governamentais a prestar contas dos resultados de suas ações, garantindo-se maior transparência e a exposição pública das políticas públicas.

Porém, a legislação não exclui totalmente a possibilidade de classificação de documentos públicos como sigilosos, pelo contrário, a lei contempla tal possibilidade, mas para casos pontuais, tais como informações referentes a projetos de pesquisa e desenvolvimento científicos ou tecnológicos cujo sigilo seja imprescindível à segurança da sociedade e do Estado.

O decreto 5.301/2004 classificava as informações e dados considerados sigilosos em quatro grupos -ultrassecretos, secretos, confidenciais e reservados. $A$ nova legislação passou a classificá-los em três grupos, extinguindo o confidencial. Houve alterações, também, nos prazos de sigilo. No caso das informações consideradas ultrassecretas, o período que era de 30 anos, foi reduzido para 25 anos. As informações secretas tiveram redução de 20, para 15 anos. Quanto às 
informações reservadas, não houve qualquer modificação de seu prazo. Diferente da legislação anterior, que trazia a possibilidade de renovação do prazo de sigilo por igual período, a nova lei contempla apenas uma única renovação de prazo, limitado apenas às informações tidas como ultrassecretas.

Outro importante caminho, inclusive com vistas à maior celeridade e alcance na obtenção de informações, é a utilização de meios de comunicação viabilizados pela tecnologia da informação e da comunicação (TICs). A utilização destas tecnologias alterou a maneira como os cidadãos utilizam a informação e interagem com ela. Seu progresso elevou a possibilidade da sociedade fiscalizar os poderes públicos e participar das tomadas de decisão. Na esfera governamental podemos citar algumas importantes ferramentas, disponíveis na internet, a serviço da população, tais como o governo eletrônico, o Portal Brasil e o Portal Transparência. Essas páginas eletrônicas disponibilizam à população informações sobre políticas públicas governamentais, além de dados referentes a gastos públicos.

A lei prevê a obrigatoriedade, ainda, de divulgação das informações através de sítios oficiais da internet, possibilitando maior celeridade e facilidade de acesso ao cidadão, inclusive portadores de deficiências. A medida, porém, não alcança os municípios cuja população seja inferior a 10.000 habitantes, o que não significa que estejam dispensados de divulgá-las.

Ainda neste contexto, um fator que não pode passar despercebido, em se tratando do uso das TICs, seria a possibilidade do uso de tais mecanismos gerarem um efeito contrário, a exclusão digital. Kliksberg (1998, p. 17) já demonstrava preocupação sobre o tema quando assim dizia:

O desenvolvimento explosivo das comunicações, cujo ponto culminante está na comunicação por computadores, abre possibilidades gigantescas de difusão de informação e intercâmbio; entretanto, amplos setores da população podem ficar fora desse processo, somando uma brecha a mais às que já existem.

Para tanto, a legislação é clara ao trazer a prescrição para que os órgãos e entidades públicas promovam, independentemente de requerimentos, a divulgação em local de fácil acesso, no âmbito de suas competências, de informações de interesse coletivo ou geral por eles produzidas ou custodiadas. Além disso, deverá promover a realização de audiências ou consultas públicas, incentivo à participação 
popular ou a outras formas de divulgação. Tal medida serve para possibilitar a todos o acesso à informação, sem exclusão daqueles ainda não inseridos neste contexto eletrônico.

Destaca-se, ainda, a preocupação da lei quanto ao desenvolvimento do controle social da administração pública, elencada como uma de suas diretrizes. O acesso a informação é essencial para garantir que as políticas públicas implementadas pelos governos sejam potencializadas - desde seu planejamento, até sua execução e avaliação - pela participação dos cidadãos.

No que se refere ao desenvolvimento da cultura de transparência na administração pública, é necessária uma estratégia consistente de implementação, que abarque ampla gama de ações coordenadas que possibilitem, facilitem e estimulem o acesso a fóruns plurais de discussões, a accountability e a proteção contra a negação de prestação de informações por parte de órgãos públicos (GRAU, 2006).

A legislação traz como regra a autorização ou a concessão imediata à informação disponível e, diante de sua impossibilidade, estabeleceu prazos para a obtenção das informações requeridas. Respeitou-se um lapso consistente, de 20 dias, prorrogável por mais 10 dias, mediante expressa justificativa. Tais prazos buscaram estabelecer um equilíbrio razoável entre a necessidade de se conseguir a informação sem, contudo, atribuir encargos impossíveis aos órgãos públicos.

Antevendo-se à ocorrência de negativa no fornecimento de informações, a legislação possibilita ao interessado interpor recurso dirigido à autoridade imediatamente superior àquela que negou a informação, que deve responder num prazo máximo de 05 dias. Se for mantida a negativa à informação, a lei prevê a esfera a qual o recurso deve ser dirigido.

Outro aspecto positivo da legislação é concernente à gratuidade dos serviços, tanto de busca quanto de fornecimento de informações. Ressalva-se, entretanto, nas hipóteses de reprodução de documentos pelo órgão ou entidade pública consultada, situação em que poderá ser cobrado exclusivamente o valor necessário ao ressarcimento do custo dos serviços e dos materiais utilizados (BRASIL, 2011c).

Será concedida a isenção de pagamento das taxas a todos aqueles cuja situação econômica não lhe permita fazê-lo sem prejuízo do sustento próprio ou da família. Muitos requerentes, ao buscarem os órgãos públicos com o fito de adquirirem informações, encontram dificuldades em descrever com precisão 
suficiente a informação que procuram. Buscando auxiliá-los, a lei prevê:

I - criação de serviço de informações ao cidadão, nos órgãos e entidades do poder público, em local com condições apropriadas para:

a) atender e orientar o público quanto ao acesso a informações;

b) informar sobre a tramitação de documentos nas suas respectivas unidades;

C) protocolizar documentos e requerimentos de acesso a informações (BRASIL, 2011c).

A lei prevê ainda no seu Art. 5을 a divulgação das informações de forma transparente, clara e em linguagem de fácil compreensão. Tal mecanismo mostra-se totalmente apropriado, pois o tecnicismo de linguagem, que afasta o cidadão comum do entendimento das leis poderia afastá-lo, também, de obter acesso à informações de seu interesse. Assim, sua linguagem deve ser clara, compreensível, pois a informação só é eficaz se o receptor recebe e interpreta corretamente a mensagem transmitida.

Se por um lado a lei trouxe inúmeras melhorias, por outro há alguns aspectos a serem melhorados. A lei prevê a apresentação do pedido de informações por qualquer meio legítimo, sem, contudo, nominá-lo. Embora pareça um avanço, não traçar diretrizes neste sentido, pode gerar confusões entre órgãos distintos quanto às formas toleradas para solicitação do pedido (oral, por escrito, meio eletrônico), podendo prejudicar o solicitante na busca de suas informações.

Outro aspecto a ser analisado seria a necessidade de declarar o nome do requerente no momento da requisição. Talvez o anonimato fosse mais viável, uma vez que sua identificação poderia ser artifício para o atraso no fornecimento de informações, por exemplo, por rivalidades políticas. Em outros países, tais como México, o procedimento requer apenas a especificação de um contato para onde se encaminhe a informação solicitada, geralmente um endereço de e-mail.

Para a divulgação das informações, os órgãos e entidades públicas deverão utilizar todos os meios e instrumentos legítimos de que dispuserem, sendo obrigatória a divulgação em sítios oficiais da rede mundial de computadores (internet). A legislação, no entanto, foi omissa ao não estabelecer o limite para tais órgão e entidades se adequarem a esta determinação. Caso entenda-se ser o prazo coincidente com aquele que a lei tem para entrar em vigor - 180 dias - cremos que não serão raros os casos de sítios com informações desencontradas ou com 
ferramentas insuficientes de acessibilidade.

Para a consecução dos objetivos propostos na lei, uma categoria será indispensável para este sucesso, os servidores públicos. Não podemos olvidar que as mudanças que a nova legislação trará impactos consideráveis em suas rotinas, no que se refere ao atendimento ao público, além de exigir uma adequação na maneira de produzir, arquivar e divulgar informações. A nova legislação, conforme Bertazzi (2011, p. 25):

[...] trará grandes impactos para a administração pública brasileira como um todo. Em especial, trará novidades para o trabalho cotidiano dos servidores públicos, e pode encontrar diversos entraves para sua implementação, uma vez que a lei de acesso à informação pode funcionar como um catalisador da mudança organizacional dentro das repartições públicas, impactando diretamente o dia a dia da organização.

Evitando dissabores, caberá a criação de um plano institucional com objetivo de coordenar a capacitação de agentes públicos, por exemplo, através do desenvolvimento de cursos de treinamento de boas práticas.

Um empecilho será o aumento do número de pedidos de informação, quando se deparar com o despreparo do aparato estatal em fornecê-las. Cabe aqui citar o exemplo de outros países, que receberam uma enxurrada de solicitações nos primeiros períodos de vigência da lei. Na Índia os cidadãos deram entrada em cerca de dois milhões de solicitações, nos primeiros dois anos e meio subsequentes à promulgação da lei de acesso à informação (MICHENER, 2011). Este volume excessivo de solicitações acarreta em atraso nas respostas dos pedidos, gerando descrédito nas instituições.

A lei se omite ao não estabelecer um parâmetro concernente aos valores a serem cobrados aos usuários pelos serviços, como custos de uma fotocópia ou a entrega de um CD contendo a informação. A medida seria essencial, principalmente para se evitar arbitrariedades e também uma razoabilidade nos valores cobrados por diferentes autoridades públicas. A omissão na estipulação de um parâmetro sobre os valores pode acarretar a fixação de valores não condizentes com a realidade, com a finalidade de afastar a busca por informações públicas.

Diante da literatura analisada neste ensaio, ficou evidenciado que a lei de acesso à informação não foi criada com o objetivo primordial de combater a 
corrupção, haja vista não conter em seu texto quaisquer disposições específicas neste sentido. Entretanto, não podemos dizer que a lei não sirva a esta finalidade uma vez que a garantia ao acesso à informação, reflete em uma maior transparência na gestão pública. Segundo Bocheneck (2008, p. 457):

A corrupção ocorre no mundo todo em graus distintos e está diretamente ligada às falhas de mecanismos de controle institucional e gerencial do Estado. A corrupção não se elimina, mas pode ser reduzida, por meio de um processo continuado e permanente de melhorias institucional, legal e cultural, que visem combater suas causas e efeitos.

Ao obter informações dos órgãos públicos, o cidadão tem a possibilidade de acompanhar como o dinheiro público está sendo utilizado e passa a ser um fiscal da correta aplicação desses recursos. "O "cidadão-fiscal" é um agente relevante no processo de fiscalização da utilização responsável dos recursos públicos, atuando como elemento inibidor da corrupção, de fraudes e da malversação de recursos públicos" (BRASIL, 2011b, p. 2).

"Com esta lei o Brasil dá mais um importante passo para a consolidação do seu regime democrático, ampliando a participação cidadã e fortalecendo os instrumentos de controle da gestão pública" (BRASIL, 2011b, p. 2). Neste sentido, Banisar (2005) afirma que os países que implementaram legislação para garantir o acesso à informação tornaram-se mais eficientes e menos suscetíveis à corrupção".

Não obstante, o livre acesso às informações produzidas pelos órgãos públicos constitui-se em um dos alicerces para a consolidação da democracia, ao fortalecer a capacidade do cidadão de participar, de modo eficaz, da tomada de decisões que os atinja.

Aduz-se, desta forma, que a edição da lei 12.527/11 terá o condão de produzir uma sociedade melhor informada, com seus direitos fundamentais mais protegidos, com gestões públicas mais transparentes e eficazes, refletindo em uma população mais consciente de seus direitos, contribuindo assim para a consolidação da democracia.

\section{CONSIDERAÇÕES FINAIS}

A lei $12.527 / 11$ se mostra um avanço na efetivação do direito ao acesso à 
informação. Dentre os aspectos relevantes, pode-se citar a estipulação de prazos razoáveis para a obtenção de informações junto aos órgãos públicos, o uso das tecnologias da informação e de comunicação como facilitador do acesso às informações públicas. Além da obrigatoriedade dos órgãos públicos promoverem a realização de audiências ou consultas públicas, incentivando a participação popular ou a outras formas de divulgação.

Contudo, a lei enfrentará algumas dificuldades no que se refere ao impacto nas rotinas dos órgãos públicos e seus servidores, devido ao possível aumento na demanda de solicitação de informações pelos cidadãos aos órgãos públicos. Outro entrave a ser superado refere-se a não estipulação de um parâmetro na cobrança de taxas, o que pode levar a cobranças abusivas e, consequentemente, a diminuição de pedidos de informação.

Para construção de uma verdadeira democracia, torna-se indispensável o acesso claro e transparente à informação pública, além de uma maior participação popular, fortalecendo assim os sistemas democráticos, resultando em ganhos para todos. O sigilo, nesta esfera democrática, propicia a corrupção e cria barreiras ao desenvolvimento. Embora o acesso à informação pública não seja suficiente para o combate à corrupção, mostra-se uma medida indispensável para a promoção de uma consciência cidadã. Outros mecanismos de participação mostram-se essenciais e complementares, tais como a criação de fóruns locais e desenvolvimento de uma cultura participativa na formulação de políticas públicas.

O acesso à informação pública e a transparência não garantem o correto funcionamento da atividade pública, mas sem eles é improvável que tal atividade ocorra sequer de maneira razoável.

\section{REFERÊNCIAS}

ALMEIDA, Alberto Carlos. Apresentação: um teste quantitativo da antropologia de Roberto Da Matta. In: . A cabeça do brasileiro. Rio de Janeiro: Record, 2007. p. 15-71.

ARAUJO, Cicero. República e democracia. Lua Nova: Revista de Cultura e Política, São Paulo, n. 51, p. 5-30, 2000. 
ARTICLE 19. Análise do projeto de lei de acesso à informação pública. 2009. Disponível em:

<http://www.artigo19.org/site/documentos/analise_do_projeto_de_lei_de_acesso_a_i nfo_publica.pdf>. Acesso em: 30 nov. 2011.

BANISAR, David. Liberdade de informação combate corrupção, diz sociedade civil. In: FÓRUM GLOBAL DE CORRUPÇÃO, 4., 2005, Brasília. Anais eletrônicos... Brasília: CGU, 2005. Disponível em: $<$ http://www.cgu.gov.br/ivforumglobal/pt_br/htm/pt-br-8.htm>. Acesso em: 24 jan. 2012.

BERTAZZI, Danilo Marasca. O projeto de lei de acesso à informação e seu impacto sobre os servidores públicos. In: ARTICLE 19. Leis de acesso a informação: dilemas da implantação. 2011. p. 25-39. Disponível em: <http://artigo19.org/>. Acesso em: 25 nov. 2011.

BOCHENECK, Antonio Cesar. Contrabando e fronteiras. In: AVRITZER, Leonardo et al. (Org.). Corrupção: ensaios e críticas. Belo Horizonte: UFMG, 2008, p. 449-470.

BRASIL. Controladoria Geral da União. Acesso à informação pública: uma introdução à Lei 12.527, de 18 de novembro de 2011. Brasília, 2011a. Disponível em: <http://www.cgu.gov.br/acessoainformacao/materiais-

interesse/CartilhaAcessoalnformacao.pdf>. Acesso em: 22 jan. 2012.

. Transparência pública. 2011b. Disponível

em:<http://www.portaltransparencia.gov.br/controleSocial/documentos/FolderTransp arencia.pdf >. Acesso em: 25 jan. 2012.

Lei no 12.527, de 18 de novembro de 2011. Regula o acesso a informações previsto no inciso XXXIII do art. $5^{\circ}$, no inciso II do $\S 3^{\circ}$ do art. 37 e no $\S 2^{\circ}$ do art. 216 da Constituição Federal; altera a Lei no 8.112, de 11 de dezembro de 1990; revoga a Lei $\mathrm{n}^{-} 11.111$, de 5 de maio de 2005, e dispositivos da Lei $\mathrm{n}^{\circ}$ 8.159, de 8 de janeiro de 1991; e dá outras providências. Diário Oficial [da] República Federativa do Brasil, Brasília, DF, 18 dez. 2011c. Disponível em: <http://www.planalto.gov.br/ccivil_03/_Ato2011-2014/2011/Lei/L12527.htm>. Acesso em: 25 nov. 2011.

CANELA, Guilherme; NASCIMENTO, Solano (Coord.). Acesso à informação e controle social das políticas públicas. Brasília: Artigo 19, 2009.

CARVALHO, José Murilo de. Cidadania no Brasil, o longo caminho. Rio de Janeiro: Civilização Brasileira, 2009.

. Passado, presente e futuro da corrupção brasileira. In: AVRITZER,

Leonardo et al. (Org.). Corrupção: ensaios e críticas. Belo Horizonte: UFMG, 2008, p. 237-242.

Pontos e bordados: escritos de história e política. Belo Horizonte: Ed. da UFMG, 1998. 
CONVENÇÃO Americana de Direitos Humanos (1969): Pacto de San José da Costa Rica. 1992. Disponível em:

$<$ http://www.pge.sp.gov.br/centrodeestudos/bibliotecavirtual/instrumentos/sanjose.ht m>. Acesso em: 10 dez. 2011.

DAHL, Robert A. Sobre a democracia. Brasília: Ed. UnB, 2001.

DELORS, Jacques. Formar a los protagonistas del futuro. 1996. 8 p. Disponível em: <http://www.unesco.org/education/nfsunesco/pdf/DELOR2_S.PDF>. Acesso em: 25 nov. 2011.

FAORO, Raymundo. Os donos do poder: formação do patronato político brasileiro. São Paulo: Globo, 2000. v. 1.

GARCIA, Emerson. A corrupção: uma visão jurídico-sociológica. 2004. Disponível em: <http://jus.com.br/revista/texto/5268/a-corrupcao>. Acesso em: 25 nov. 2011.

GRAU, Nuria Cubil. Responsabilização pelo controle social. In: BRESSERPEREIRA, Luiz Carlos; GRAU, Nuria Cubill (Coord.). Responsabilização na administração pública. São Paulo: Fundap, 2006. p. 263-322.

JARDIM, José Maria. Transparência e opacidade do estado no Brasil: usos e desusos da informação governamental. Niterói: Ed. da UFF, 1999.

JASMIM, Marcelo C. Alexis de Tocqueville: a historiografia como ciência da política. 2. ed. Belo Horizonte: Ed. UFMG; Rio de Janeiro: IUPERJ, 2005.

KLIKSBERG, Bernardo. Repensando o Estado para o desenvolvimento social: superando dogmas e convencionalismos. São Paulo: Cortez, 1998.

KLITGAARD, Robert. A corrupção sob controle. Rio de Janeiro: J. Zahar, 1994.

LOPES, Cristiano Aguiar. Acesso a informação pública para a melhoria da qualidade dos gastos públicos: literatura, evidências empíricas e o caso brasileiro. Cadernos Finanças Públicas, Brasília, n. 8, p. 5-40, dez. 2007. Disponível em: <http://www.esaf.fazenda.gov.br/esafsite/publicacoes-esaf/cadernofinancas/CFP8/CFP_n8_art1.pdf>. Acesso em: 20 nov. 2011.

. Os impactos da transparência governamental na efetividade dos gatos públicos e na consolidação da democracia. In: CONGRESSO BRASILEIRO DE CIÊNCIAS DA COMUNICAÇÃO, 32., 2009, Curitiba. Anais... Curitiba: Intercom, 2009. Disponível em:

<http://www.intercom.org.br/papers/nacionais/2009/resumos/R4-2191-1.pdf >. Acesso em: 25 nov. 2011.

MANZANO FILHO, Gabriel. OEA defende o direito à informação. 2012. Disponível em:

$<\mathrm{http}: / /$ www.mndh.org.br/index.php?option=com_content\&task=view\&id=113\&ltemid $=45$ >. Acesso em: 24 jan. 2012 .

MENDEL, Toby. Liberdade de informação: um estudo de direito comparado. 2. ed. Brasília: UNESCO, 2009. 
MICHENER, Greg. Liberdade de informação: uma síntese dos dilemas de conformidade suas possíveis soluções. In: ARTICLE 19. Leis de acesso a informação: dilemas da implantação. 2011. p. 25-39. Disponível em: <http://artigo19.org/>. Acesso em: 25 nov. 2011.

MÜLLER, Friedrich. Quem é o povo? A questão fundamental da democracia. 2. ed. São Paulo: Max Limond, 2000.

ORGANIZAÇÃO DAS NAÇÕES UNIDAS. O que causa a corrupção? Disponível em: <http://www.unodc.org/brazil/pt/programasglobais_corrupcao_causa.html >. Acesso em: 28 nov. 2011.

POULANTZAS, Nicos. O Estado, o poder e o socialismo. Rio de Janeiro: Graal, 1985.

SANTOS, Boaventura de Souza. Reiventar a democracia: pré-contratualismo e o pós-contratualismo. 1998. Disponível em:

<http://www.ces.fe.uc.pt/publicacoes/oficina/107/107.pdf>. Acesso em: 30 nov. 2011.

SANTOS, Wanderley Guilherme dos. Democracia. In: AVRITZER, Leonardo et al. (Org.). Corrupção: ensaios e críticas. Belo Horizonte: UFMG, 2008. p. 125-130.

SILVA, Marcos Fernandes Gonçalves da. A economia política da corrupção.

Estudos Econômicos da Construção, Rio de Janeiro, v. 2, p. 1-22, 1996.

Disponível em:

$<$ http://bibliotecadigital.fgv.br/dspace/bitstream/handle/10438/1957/TD60.pdf?sequenc $\mathrm{e}=1>$. Acesso em: 25 nov. 2011.

STIGLITZ, Joseph. Transparency in government. In: WORLD BANK INSTITUTE. The right to tell: the role of mass media in economic development. Washington, 2002. Part.1, p. 27-44. Disponível em:

<http://books.google.com.br/books?id=56punuel7G0C\&pg=PA22\&hl=pt-

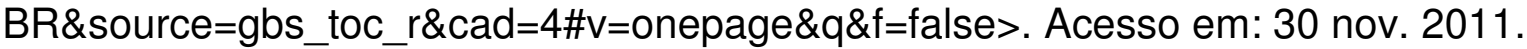

TOCQUEVILLE, Alexis de. A democracia na América. 4. ed. Belo Horizonte: Itatiaia, 1998.

VIANA, Francisco José de Oliveira. Instituições políticas brasileiras. Brasília. Conselho Editorial do Senado Federal, 1999.

\section{Title}

Law of Access to Information: in Search of Transparency and Combating Fight Corruption

\section{Abstract}

Introduction: The right to access information has been increasingly highlighted. Its importance has been emphasized by scholars, by the experts, the media and governments. Objective: The article aims to analyze the scope of Law 12.527/11 in combating corruption 
and contribution to the consolidation of democracy in Brazil.

Methodology: As a research technique was adopted a qualitative approach, using literature review and documentary research.

Results: The law $12.527 / 11$ shown an improvement in the effectiveness of the right to information access. Among the relevant aspects, highlight the stipulation of reasonable deadlines for obtaining information from public agencies, the use of information and communication technologies facilitating access to public information.

Conclusions: It is concluded that to build a true democracy, becomes indispensable the clear and transparent access to public information, and greater popular participation, thereby strengthening democratic systems.

Keywords: Law of access to Information. Public transparency. Corruption.

\section{Título}

Ley de acceso a la información: en busca de transparencia y lucha contra la corrupción

\section{Resumen}

Introducíon: El derecho de acceso a la información se ha ganado una creciente prominente. Su importancia ha sido destacada por los estudiosos, de los expertos, los medios de comunicación y relacioné por los gobiernos.

Objetivo: El artículo tiene como objetivo analizar los alcances de la Ley 12.527/11 en la lucha contra la corrupción y su contribución a la consolidación de la democracia en Brasil.

Metodología: Cómo la investigación técnica y una aproximación cualitativa, utilizando una revisión de literatura y investigación documental.

Resultados: La Ley 12.527/11 muestra un avance en la realización del derecho al acceso a la información. Entre los aspectos relevantes, se puede citar condición de los plazos razonables para obtener información los organismos públicos, el uso de tecnologías de información y comunicación que faciliten el acceso a la información pública.

Conclusiones: Llegamos a la conclusión de que la construcción de una verdadera democracia, es esencial para un acceso claro y transparente a la información pública, además de una mayor participación popular, fortaleciendo así los sistemas democráticos.

Palabras clave: Ley de acceso a la información. La transparencia pública. Corrupción.

Recebido em: 26.10.2012

Aceito em: 09.09.2013 